\title{
Inheritance of the Easy-peeling Pellicle Trait of Japanese Chestnut Cultivar Porotan
}

\author{
Norio Takada ${ }^{3}$, Sogo Nishio, Masahiko Yamada, Yutaka Sawamura ${ }^{1}$, \\ Akihiko Sato' ${ }^{2}$ Toshio Hirabayashi, and Toshihiro Saito \\ National Institute of Fruit Tree Science, 2-1 Fujimoto, Tsukuba, Ibaraki \\ 305-8605, Japan
}

Additional index words. breeding, Castanea crenata, gene, genetic resources, nut

\begin{abstract}
Porotan' is a Japanese chestnut cultivar (Castanea crenata Sieb. et Zucc.) that was selected from offspring of the cross 550-40 $\times$ 'Tanzawa' and released in 2006. Its nut is distinguished by a pellicle that is easy to peel after roasting; previously, all Japanese chestnut cultivars were thought to have a pellicle that was difficult to peel. Both 550-40 and 'Tanzawa' are Japanese chestnuts, and 550-40 is a selection descended from 'Tanzawa'. Both 550-40 and 'Tanzawa' have a pellicle that is difficult to peel. Among 59 offspring of a cross of 550-40 $\times$ 'Tanzawa', 12 had an easy-peeling pellicle and 47 had a difficult-peeling pellicle; this ratio is not significantly different from the $1: 3$ expected ratio for monogenic inheritance based on a chi-square test at $\boldsymbol{P}=0.05$. A half-diallel cross without selfings was made among 'Porotan', 'Tanzawa', and 'Tsukuba'. All the offspring from 'Tanzawa' $\times$ 'Tsukuba' and from 'Tsukuba' $\times$ 'Porotan' had a difficult-peeling pellicle; in contrast, 39 offspring from 'Tanzawa' $\times$ 'Porotan' segregated in a ratio of 19 difficult-peeling pellicle to 20 easy-peeling pellicle, which is not significantly different from the expected 1:1 ratio for monogenic segregation based on a chi-square test at $P=0.05$. These results suggest that the easy-peeling pellicle trait of 'Porotan' is controlled by a major recessive gene at a single locus. We designated the pellicle peelability locus as $P / p$. According to this model, the 'Tsukuba' genotype is homozygous-dominant (PP), the 'Tanzawa' genotype is heterozygous $(P p)$, and the 'Porotan' genotype is homozygousrecessive $(p p)$.
\end{abstract}

Worldwide, four chestnut species are grown commercially. Japanese chestnut (Castanea crenata Sieb. et Zucc.) is of Japanese and Korean origin, and many local varieties have been developed and distributed in temperate regions of Japan and the Korean peninsula (Rutter et al., 1990). Chinese chestnut (C. mollissima $\mathrm{Bl}$.) is grown mostly in China and the northern Korean peninsula. European chestnut ( $C$. sativa Mill.) is also commercially cultivated in Europe and West Asia, including Turkey. American chestnut $(C$. dentata Borkh.) was a very common species in eastern North America in the early 20th century, before it was nearly eliminated by the accidental introduction of chestnut blight [Cryphonectria parasitica (Murrill) Barr] (Avanzato, 2009). Japanese chestnut differs from Chinese chestnut in morphological characteristics such as nut size, leaf shape, and hair density on young leaves (Woodroof, 1979). Japanese chestnut cultivars are believed to

Received for publication 16 Feb. 2012. Accepted for publication 27 Apr. 2012.

${ }^{1}$ Present address: Headquarters, National Agriculture and Food Research Organization, Tsukuba 305-8607, Japan.

${ }^{2}$ Present address: Grape and Persimmon Research Station, National Institute of Fruit Tree Science, National Agriculture and Food Research Organization. Akitsu, Higashihiroshima 739-2494, Japan. ${ }^{3}$ To whom reprint requests should be addressed; e-mailntakada@affrc.go.jp. have been developed from wild chestnuts of Japanese origin (Kotobuki, 1994). This hypothesis is supported by the considerable genetic distance between local Japanese chestnut cultivars and Chinese chestnut as determined using amplified fragment length polymorphism markers (Yamamoto et al., 1998).

Japanese chestnut is adapted to the climate in Japan and has been an important source of food for the Japanese people since ancient times (Sawamura, 2006). Today it is produced mostly by commercial cultivation. According to FAOSTAT (2011), the chestnut cultivation area in Japan was 21,700 ha in 2010. All of the Japanese chestnut cultivars currently used for domestic production have a pellicle that is difficult to peel from the kernel (hereafter, "difficult-peeling") even after heating, which distinguishes them from many Chinese chestnut cultivars. The pellicle of Japanese chestnut is often removed by hand using a knife, which is a laborious and costly process.

A Japanese chestnut breeding program was started in 1947 at the National Institute of Fruit Tree Science (NIFTS). One of the initial targets of the program was to release Japanese chestnut cultivars having an easypeeling pellicle in combination with large nut size. The difficult-peeling pellicle trait was long believed to be a characteristic specific of all Japanese chestnut (Kikuchi, 1948; Miller et al., 1996). The breeding had been carried out under the assumption that no offspring having an easy-peeling pellicle would arise from crosses among Japanese chestnut cultivars, although there might be small genetic differences in pellicle peelability. Thus, the chestnut breeders focused on quantitative improvement in pellicle peelability in the progeny of crosses among Japanese chestnuts.

In 2006, Shoda and colleagues reported a new evaluation method, termed the hightemperature oil peeling (HOP) method, in which pellicle peelability could be evaluated after deep frying the nuts for only $2 \mathrm{~min}$ (Shoda et al., 2006). This method efficiently heats the nut surface, which allows more rapid evaluation of the pellicle peelability. Using the HOP method, the breeders evaluated peelability in selections and cultivars and surprisingly discovered that one selection had an exceptionally easy-peeling pellicle. This selection was ultimately released as 'Porotan' in 2006 (Saito et al., 2009).

So far, no Japanese chestnut cultivars or selections other than 'Porotan' have been found to have the easy pellicle peelability found in Chinese chestnut cultivars (Saito et al., 2009). Consequently, we hypothesized that the easy-peeling pellicle trait in 'Porotan' was controlled by one or more major recessive genes present in some Japanese chestnut cultivars. 'Porotan' was an offspring from a cross between 'Tanzawa' and 550-40, a selection derived from 'Tanzawa' (Fig. 1), so we hypothesized that 'Tanzawa' carries a recessive gene for the easy-peeling pellicle trait.

The objectives of the present study were 1) to elucidate the mode of inheritance of the easy-peeling pellicle trait of 'Porotan'; and 2) to trace the origin of the gene(s) controlling the trait. Tree-fruit and nut crops such as chestnuts are large trees, and the seedlings do not bear fruit or nuts for several years after planting, so a large-scale crossing experiment is very costly and time-consuming. Therefore, in the present study, we performed all possible crosses among a set of three parents presumed to have different genotypes but did not include reciprocal crosses or selfings (i.e., a modified half-diallel cross).

\section{Materials and Methods}

\section{Plant materials}

Cross of 550-40 × 'Tanzawa', the parents of 'Porotan'. 'Porotan' was obtained from a cross of 550-40 $\times$ 'Tanzawa' made in 1991 (Fig. 1). 'Porotan' was selected primarily because of its large nut size and high eating quality. The other sib seedlings from the original cross were discarded and were not evaluated for pellicle peelability. The HOP method was developed later, so 'Porotan' was not evaluated for this trait until long after its initial selection. Consequently, we remade the cross 550-40 $\times$ 'Tanzawa' from 2004 to 2006 . The obtained cross-seedlings were grown in the orchard of NIFTS.

Modified half-diallel cross among 'Porotan', 'Tanzawa', and 'Tsukuba'. A modified halfdiallel cross was made among 'Porotan', 
'Tanzawa', and 'Tsukuba' from 2004 to 2006. 'Tsukuba' was an offspring from a cross of 'Ganne' $\times$ 'Hayadama', both of which are local Japanese chestnut cultivars of Japanese origin. 'Tsukuba' was released in 1959 and is still a leading commercial cultivar. It was used repeatedly as a crossing parent in the NIFTS breeding program; however, the crosses did not yield any selections having an easy-peeling pellicle.

Therefore, 'T sukuba' was used as a crossing parent in the diallel based on the hypothesis that it carries no genes for the easy-peeling pellicle trait. As described, we hypothesized that 'Tanzawa' carries a recessive gene for the easy-peeling pellicle trait.

When the progeny seedlings from the crosses were 2 years old, they were planted at a spacing of $2 \mathrm{~m} \times 5 \mathrm{~m}$ in the NIFTS orchard in Tsukuba, Japan. In 2010, the trees bore nuts, which were evaluated for pellicle peelability by using the HOP method described subsequently.

Ancestors of 'Porotan', 'Tanzawa', and 'Tsukuba'. In 2004, the ancestors of 'Porotan', 'Tanzawa', and 'Tsukuba' (Fig. 1) were evaluated for pellicle peelability by using the HOP method. 'Moriwase' and 'Kairyoutoyotama' were later found to be identical based on simple sequence repeat marker analysis (Nishio et al., 2011). The trees were sampled from the orchard at NIFTS, and 'Tsukuba' were 26 years old at the time of sampling.

Evaluation of pellicle peelability. Ten nuts harvested from each cultivar, selection, and offspring plant were evaluated for pellicle peelability. The nuts were stored at $5{ }^{\circ} \mathrm{C}$ for $\approx 2$ months after harvesting. To prepare the nuts for evaluation, the shells were removed and the nuts were treated in oil at $190^{\circ} \mathrm{C}$ for $2 \mathrm{~min}$, according to the HOP method (Shoda et al., 2006). The pellicle peelability of each nut was evaluated after the heat treatment by hand-peeling with a paring knife.

Nuts having a pellicle that could be easily peeled from the entire nut without scraping any part of the nut surface were classified as easy-peeling. In contrast, nuts that could not be peeled without scraping the nut surface were classified as difficult-peeling (Fig. 2).

\section{Results and Discussion}

Pellicle peelability in 'Porotan', 'Tanzawa', 'Tsukuba', and their ancestors. The pellicle peelability of all the ancestral cultivars/ selections of 'Porotan', including 'Tanzawa', was classified as difficult-peeling (Table 1). 'Tsukuba' and its parents, 'Ganne' and 'Hayadama', which are local cultivars of Japanese origin, were also classified as difficult-peeling. 'Porotan' alone was classified as easy-peeling. We did not find any within-plant variation for peelability.

Segregation for pellicle peelability in the offspring of 550-40 $\times$ 'Tanzawa'. In a population of 59 offspring from crosses of 550-40 $\times$ 'Tanzawa', pellicle peelability segregated in a ratio of 47 difficult-peeling to 12 easy-peeling
(Table 2). Within-plant variation for peelability was not found. The observed segregation ratio was tested by chi-square goodness-of-fit tests of hypotheses of 1:1 and 1:3 segregation ratios. At $P=0.05$, the $1: 1$ hypothesis was rejected and the 1:3 hypothesis was not rejected. We designated the pellicle peelability locus as $P / p$. If we postulate a single recessive gene for easy-peeling pellicle $(p)$ and a dominant gene for difficult-peeling pellicle $(P)$, the results support a model in which both 550-40 and 'Tanzawa' are heterozygotes $(P p)$, and the plants classified as easy-peeling, including 'Porotan', are homozygous-recessive ( $p p$ ) (Fig. 1).

These results indicate that the easy-peeling trait in 'Porotan' was not a new mutation in the full-sib population from which it was derived and that the inheritance of peelability is nuclear rather than cytoplasmic.

Segregation of pellicle peelability in the offspring of a modified half-diallel cross among 'Porotan', 'Tanzawa', and 'Tsukuba'. In a population of 39 offspring from 'Tanzawa' $x$ 'Porotan', 19 were classified as difficultpeeling and 20 as easy-peeling (Table 2). Within-plant variation for peelability was not found. When the segregation ratio was tested by a chi-square test of the hypothesis of a 1:1 segregation ratio, the hypothesis was not rejected at $P=0.05$. All the offspring from 'Tanzawa' $\times$ 'Tsukuba' $(\mathrm{n}=20)$ and from 'Tsukuba' $\times$ 'Porotan' $(n=40)$ were classified as difficult-peeling (Table 2). These segregation ratios provide further evidence that the inheritance of peelability is nuclear rather than cytoplasmic and that the easy-peeling pellicle trait is controlled by a single recessive gene. These data are consistent with the model described and support the hypothesis that the 'Tsukuba' genotype is homozygous-dominant $(P P)$, the 'Tanzawa' genotype is heterozygous $(P p)$, and the 'Porotan' genotype is homozygousrecessive ( $p p)$ (Fig. 1).

The origin of the easy-peeling pellicle trait in 'Porotan'. Takada et al. (2010) reported that all the nuts from 'Porotan' trees pollinated with leading Japanese chestnut cultivars in Japan had easy-peeling pellicles after heating by the HOP method. In contrast, Chinese chestnut cultivars bore nuts with difficult-peeling pellicles when pollinated with Japanese chestnut cultivars (Osaki and Sasou, 1942), although some exceptions have been reported (Iimori and Ohta, 1943; Kajiura, 1932). In addition, 'Porotan' accumulated more phenolic compounds in pellicle tissue than did Chinese chestnut cultivars (Sato et al., 2010); this is in contrast to a previous report (Tanaka et al., 1981) that the difference in adhesiveness between the pellicle and kernel were characterized by the amount of phenolic compounds in pellicle tissue, which was lower in easy-peeling Chinese chestnut than difficult-peeling Japanese chestnut. Thus, the mechanism underlying the easy-peeling pellicle trait of 'Porotan'

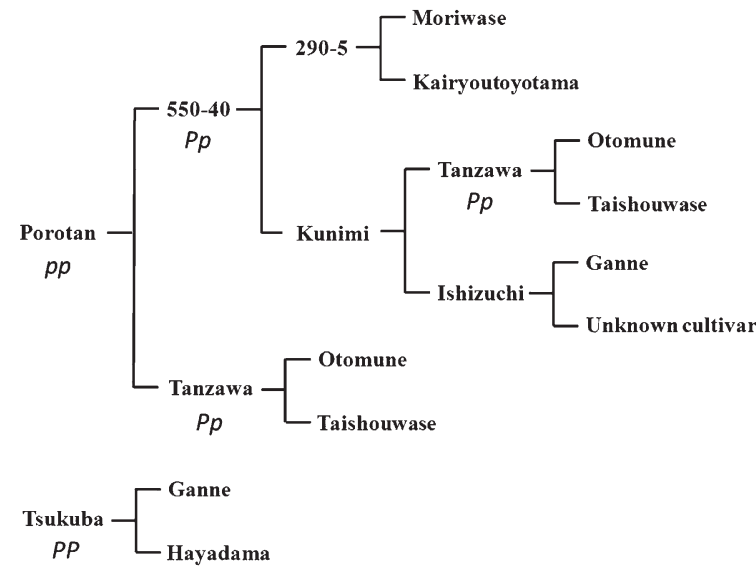

Fig. 1. The pedigrees of 'Porotan' and 'Tsukuba'.

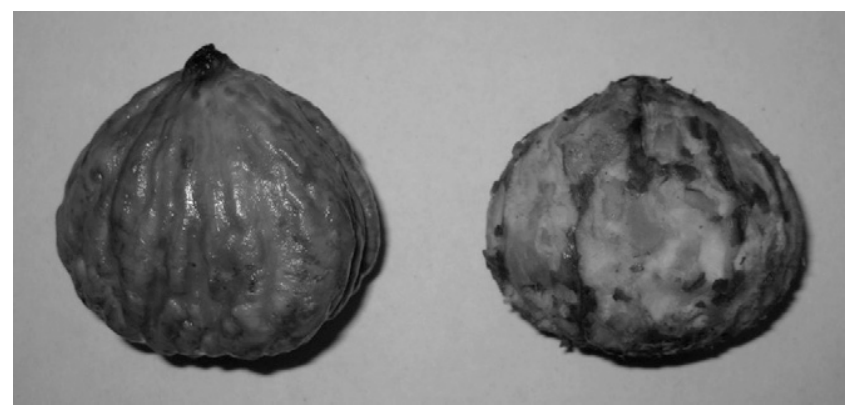

Fig. 2. Peeled nuts of 'Porotan' (left) and 'Tsukuba' (right). 'Porotan' has a pellicle that can be easily peeled from the entire nut without scraping any part of the nut surface [easy-peeling (EP)], but 'Tsukuba' cannot be peeled without scraping the nut surface [difficult-peeling (DP)]. 
Table 1. Origin and pellicle peelability of 'Porotan', 'Tsukuba', and their ancestral cultivars and selections.

\begin{tabular}{lllc}
\hline Cultivar/selection & $\begin{array}{c}\text { Collection site } \\
\text { (JP accession no. })^{\mathrm{z}}\end{array}$ & \multicolumn{1}{c}{ Origin } & $\begin{array}{c}\text { Pellicle } \\
\text { peelability }\end{array}$ \\
\hline Ganne & NIFTS $(113846)$ & Local cultivar of Japanese origin & DP \\
Hayadama & NIFTS (113855) & Local cultivar of Japanese origin & DP \\
Kairyoutoyotama & NIFTS (113865) & Local cultivar of Japanese origin & DP \\
Moriwase & NIFTS (176784) & Local cultivar of Japanese origin & DP \\
Otomune & NIFTS (173885) & Local cultivar of Japanese origin & DP \\
Taishouwase & NIFTS (113897) & Local cultivar of Japanese origin & DP \\
Ishizuchi & NIFTS (113862) & $\mathrm{F}_{1}$ of Ganne $\times$ unknown cultivar & DP \\
Kunimi & NIFTS (176783) & $\mathrm{F}_{1}$ of Tanzawa $\times$ Ishizuchi & DP \\
Porotan & NIFTS & $\mathrm{F}_{1}$ of 550-40 $\times$ Tanzawa & EP \\
Tanzawa & NIFTS $(113902)$ & $\mathrm{F}_{1}$ of Otomune $\times$ Taishouwase & DP \\
Tsukuba & NIFTS $(113909)$ & $\mathrm{F}_{1}$ of Hayadama $\times$ Ganne & DP \\
$290-5$ & NIFTS & $\mathrm{F}_{1}$ of Moriwase $\times$ Kairyoutoyotama & DP \\
$550-40$ & NIFTS & $\mathrm{F}_{1}$ of $290-5 \times$ Kunimi & DP \\
\hline All & & &
\end{tabular}

All the cultivars/selections are C. crenata Sieb. et Zucc.

${ }^{\mathrm{z}}$ Numbers indicated in parentheses are JP accession numbers from GeneBank.

${ }^{y} \mathrm{DP}$ (difficult-peeling) = the pellicle cannot be completely removed without scraping the nut surface. EP (easy-peeling) $=$ the pellicle can be easily removed from the entire nut without scraping any part of the nut surface.

NIFTS $=$ National Institute of Fruit Tree Science.

Table 2. Segregation of pellicle peelability in offspring of 550-40 × 'Tanzawa' and in modified half-diallel crosses among 'Porotan', 'Tanzawa', and 'Tsukuba'.

\begin{tabular}{|c|c|c|c|c|c|c|c|c|c|}
\hline \multirow[b]{3}{*}{ Cross } & & & \multirow[b]{3}{*}{$\mathrm{n}^{\mathrm{z}}$} & & & \multicolumn{4}{|c|}{$\chi^{2}$ tests of segregation ratios } \\
\hline & & & & \multicolumn{2}{|c|}{ Pellicle peelability } & \multicolumn{2}{|c|}{$1: 1$} & \multicolumn{2}{|c|}{$1: 3$} \\
\hline & & & & EP & DP & $\chi^{2}$ & $P$ value & $\chi^{2}$ & $P$ value \\
\hline$\overline{550-40}$ & $x$ & Tanzawa & 59 & 12 & 47 & 20.76 & $<0.01$ & 0.68 & 0.41 \\
\hline Tanzawa & $x$ & Porotan & 39 & 20 & 19 & 0.03 & 0.87 & 14.37 & $<0.01$ \\
\hline Tanzawa & $x$ & Tsukuba & 20 & 0 & 20 & & & & \\
\hline Tsukuba & $x$ & Porotan & 40 & 0 & 40 & & & & \\
\hline
\end{tabular}

${ }^{2}$ Number of seedlings evaluated.

${ }^{\mathrm{y}} \mathrm{EP}$ (easy-peeling) = the pellicle can be easily removed from the entire nut without scraping any part of the nut surface. DP (difficult-peeling) = the pellicle cannot be completely removed without scraping the nut surface.

may be different from that found in Chinese chestnut.

The parents of 550-40 $(P p)$ are 290-5 and 'Kunimi', and the parents of 'Tanzawa' $(P p)$ are 'Otomune' and 'Taishouwase'. Thus, at least one of the parents in each pair is expected to also be heterozygous $(P p)$ for the easy-peeling trait. 'Kunimi' is an offspring of 'Tanzawa' $\times$ 'Ishizuchi'; therefore, it is possible that the origin of the $p$ gene in 550-40 is 'Tanzawa'. If so, 'Kunimi' should be heterozygous $(P p)$ for the easy-peeling trait. On the other hand, it is possible that one of the other ancestral cultivars of 290-5 or 'Kunimi' is the source of the $p$ gene; however, no easy-peeling offspring have been found in descendants from those cultivars in the NIFTS breeding program, suggesting that those ancestral cultivars possibly do not carry $p$.

The results of the present study have revealed that some local Japanese chestnut cultivars are heterozygous for a recessive gene conferring the easy-peeling pellicle trait. Local cultivars developed throughout Japan have a difficult-peeling pellicle. Assuming random mating in the population of local Japanese chestnut cultivars, a low frequency of the recessive gene would result in a very low frequency of recessive homozygotes, that is, having an easy-peeling pellicle. In contrast, inbreeding is common in fruit and nut tree breeding, including NIFTS chestnut breeding, as shown by the pedigree of 'Porotan' (Fig. 1). Inbreeding increases the chances of obtaining recessive homozygotes and, as reported here, produced the homozygous recessive genotype for easy-peeling pellicle found in 'Porotan'.

As a breeding strategy to develop new cultivars with easy-peeling pellicles, crosses using the homozygous cultivar Porotan or heterozygotes such as 'Tanzawa' and 550-40 are recommended. However, productivity is generally reduced by inbreeding depression in cross-pollinated plants, including chestnuts. At present, we have identified very few cultivars or selections carrying the easypeeling pellicle gene, so it is possible that inbreeding depression hinders the achievement of high productivity in crosses among the limited descendants of these cultivars and selections. Therefore, identifying other local cultivars possessing the recessive gene is desirable for avoiding inbreeding depression.

DNA markers can be developed for major genes and would be useful in this situation. If a DNA marker linked with the recessive gene for easy-peeling pellicle can be developed, then existing genetic resources could be screened for those carrying the gene. In addition, offspring could be selected for peelability at the seedling stage. Markerassisted preliminary selection of seedlings planting into the selection orchard would markedly reduce breeding costs by increasing the number of individuals in the orchard carrying the trait, thus increasing the chance of obtaining desirable genotypes in subsequent crosses and selections. for the pellicle peelability trait before trans-

\section{Literature Cited}

Avanzato, D. 2009. Following chestnut footprints (Castanea spp.): Cultivation and culture, folklore and history, tradition and uses. ISHS, Leuven, Belgium.

FAOSTAT. 2011. Food and Agriculture Organization of the United Nations. Rome, Italy. 23 Feb. 2012. <http://faostat.fao.org/site/567/Desktop Default.aspx $>$.

Iimori, M. and T. Ohta. 1943. Study on xenia of Chinese chestnut. J. Jpn. Soc. Hort. Sci. 14:213-221 [in Japanese].

Kajiura, M. 1932. Studies on Chinese chestnuts produced on Kochi Prefecture. J. Okitsu Hort. Soc. 28:64-71.

Kikuchi, A. 1948. Chestnut, p. 231-245. Pomology, 1 [in Japanese]. Yokendo, Tokyo, Japan.

Kotobuki, K. 1994. Chestnut, p. 53-55. In: Jpn. Soc. Hort. Sci. (eds.). Horticulture in Japan. Asakura Publishing Co. Ltd., Tokyo, Japan.

Miller, G., D.D. Miller, and R.A. Jaynes. 1996. Chestnuts. p. 99-123. In: Janick, J. and J.N. Moore (eds.). Fruit breeding. Vol. III. Nuts. Wiley, Inc., New York, NY.

Nishio, S., T. Yamamoto, S. Terakami, Y. Sawamura, N. Takada, and T. Saito. 2011. Genetic diversity of Japanese chestnut cultivars assessed by SSR markers. Breed. Sci. 61:109-120.

Osaki, M. and H. Sasou. 1942. Studies of removal of pellicles in Chinese chestnut. J. Jpn. Soc. Hort. Sci. 13:229-232 [in Japanese].

Rutter, P.A., G. Miller, and J.A. Payne. 1990. Chestnuts (Castanea), p. 761-788. In: Moore, J.N. and J.R. Ballington Jr. (eds.). Genetic resources of temperate fruit and nut crops I. International Society for Horticultural Science, Wageningen, The Netherlands.

Saito, T., K. Kotobuki, Y. Sawamura, K. Abe, O. Terai, M. Shoda, N. Takada, Y. Sato, T. Hirabayashi, A. Sato, T. Nishibata, Y. Kashimura, T. Kozono, H. Fukuda, K. Kihara, K. Suzuki, and M. Uchida. 2009. New Japanese chestnut cultivar 'Porotan'. Bull. Natl. Inst. Fruit Tree Sci. 9:1-9 [in Japanese with English abstract].

Sato, A., K. Tanaka, N. Takada, Y. Sawamura, and T. Hirabayashi. 2010. Comparison of phenolic content of easily removed pellicle of Japanese chestnut 'Porotan' with other Japanese and Chinese chestnut cultivars. J. Jpn. Soc. Hort. Sci. 79:258-262.

Sawamura, Y. 2006. Chestnut, p. 82-85. In: Jpn. Soc. Hort. Sci. (eds.). Horticulture in Japan 2006. Shoukadoh, Kyoto, Japan.

Shoda, M., N. Takada, T. Saito, Y. Sawamura, and K. Kotobuki. 2006. A method for quickly removing pellicles from chestnuts by deep frying cooking oil. Bull. Natl. Inst. Fruit Tree Sci. 5:2127 [in Japanese with English summary].

Takada, N., Y. Sawamura, S. Nishio, and T. Saito. 2010. Influence of pollen parents on removability of pellicle and fruit weight of chestnut cultivar 'Porotan'. Acta Hort. 866:239-242.

Tanaka, K., K. Kotobuki, and N. Kakiuchi. 1981. Numerization of peeling easiness and role of phenolic compounds of the pellicle in the adhesion between the pellicle and embryo in comparison of Japanese (Castanea crenata Sieb. et Zucc.) and Chinese (Castanea mollissima Blume) chestnuts. J. Jpn. Soc. Hort. Sci. 50: 363-371.

Woodroof, J.G. 1979. Tree nuts: Production processing products. 2nd Ed. Avi Pub., Westport, CT. p. 241.

Yamamoto, T., T. Shimada, K. Kotobuki, Y. Morimoto, and M. Yoshida. 1998. Genetic characterization of Asian chestnut varieties assessed by AFLP. Breed. Sci. 48:359-363. 